\title{
Transnacionalismo, juventude rural e a busca de reconhecimento
}

Maria Zenaide Alves'

Juarez Tarcísio Dayrell"

\section{Resumo}

Este texto trata de uma parcela da juventude brasileira contemporânea que tem vivenciado singularidades no processo de transição para a vida adulta ocasionadas pelas migrações internacionais. São jovens moradores de um município rural marcado pelo transnacionalismo. Nosso objetivo é problematizar a condição juvenil nesse contexto, buscando evidenciar os elementos empíricos do transnacionalismo e sua influência na vida dos jovens, na transição para a vida adulta e na busca de reconhecimento. Os dados utilizados na análise são resultados de um estudo com jovens de famílias transnacionais, aqui identificados como filhos da migração. 0 estudo foi desenvolvido entre 2009 e 2013 por meio de uma etnografia, utilizando como principais formas de coleta de dados a observação direta e participante. A pesquisa de campo foi desenvolvida durante oito meses, em um município rural da região mineira de Governador Valadares, quando também foram aplicados questionários e entrevistas individuais e coletivas. Os resultados apresentados neste artigo evidenciam: as principais características do transnacionalismo nesse local de origem das migrações internacionais; aspectos da condição juvenil, das famílias transnacionais, da transição para a vida adulta e a busca dos jovens por ser alguém na vida, compreendida como expressão da busca por reconhecimento.

\section{Palavras-chave}

Juventude rural - Transnacionalismo - Reconhecimento.
I- Universidade Federal de Goiás, Catalão, GO, Brasil.

Contato: zenpiaui@yahoo.com.br II- Universidade Federal de Minas Gerais, Belo Horizonte, MG, Brasil. Contato: juareztd@gmail.com 


\title{
Transnationalism, Rural Youth and Its Search for Recognition
}

\author{
Maria Zenaide Alves ' \\ Juarez Tarcísio Dayrell "
}

\begin{abstract}
This work is concerned to a part of the Brazilian contemporary youth which has been experiencing singularities in the process of reaching adulthood due to occasional international migration. They are young people allocated in a rural district marked by transnationalism. Our purpose is to question the youth condition in this context, aiming at showing the empirical elements of transnationalism and its influence in the life of these young people, in regards to their transition to adult life, as well as their search for recognition. The data used in the analysis was taken from the results achieved in a study with young people from transnational families, here identified as Sons of migration. Such study was developed during the years of 2009 to 2013 by means of ethnography, in which the main procedures used were data collection and direct and participant observation. The field research was developed during eight months, in a rural district in the region of Governador Valadares, Minas Gerais, where questionnaires and personal and collective interviews were also conducted. The results to be presented in this article show, firstly, the main characteristics of transnationalism in this place of international migration, as well as features of their youth condition, transnational families, transition to adulthood, and, last but not least, these young people's willingness to be someone, which is interconnected to their search for recognition.
\end{abstract}

\section{Keywords}

Rural Youth - Transnationalism - Recognition

I- Universidade Federal de Goiás,

Catalão, GO, Brasil.

Contact: zenpiaui@yahoo.com.br

II- Universidade Federal de Minas Gerais, Belo Horizonte, MG, Brasil.

Contact: juareztd@gmail.com 
As desigualdades e diferenças que marcam os territórios do campo e da cidade no Brasil acabam por estigmatizar e inferiorizar os moradores do campo perante outros grupos territoriais. Os limites sociais, econômicos e culturais a que estão expostos os povos do campo, ou mesmo do interior do Brasil, ainda constituem um dos fatores de desigualdade interna, de exclusão e de invisibilização das populações rurais. Nesse contexto, os jovens têm forjado formas próprias de lidar com tal situação e procurado buscar alternativas que lhes permitam superar esse quadro e ser vistos e reconhecidos socialmente ou, nos dizeres deles próprios, que lhes permitam "ser alguém na vida".

Tomando como sujeitos de análise jovens moradores de um município rural brasileiro, este texto se propõe a discutir alguns aspectos da condição juvenil em um contexto marcado pela cultura da migração e as estratégias utilizadas pelos jovens na busca por reconhecimento. Ao falar em condição juvenil, estamos nos referindo a uma dupla dimensão. Condição origina-se do latim conditio, e refere-se à maneira de ser, à situação de alguém perante a vida, perante a sociedade. Mas também se refere às circunstâncias necessárias para que se verifique essa maneira ou tal situação. Assim, a condição juvenil refere-se ao modo como uma sociedade constitui e atribui significado a esse momento do ciclo da vida, no contexto de uma dimensão histórico-geracional, mas também à sua situação, ou seja, o modo como tal condição é vivida a partir dos diversos recortes referidos às diferenças sociais - classe, gênero, etnia etc. A análise permite levar em conta tanto a dimensão simbólica como os aspectos fáticos, materiais, históricos e políticos nos quais a produção social da juventude se desenvolve (MARGULIS, 2000; ABRAMO, 2005; DAYRELL, 2005; ALVES, 2013). ${ }^{1}$

Buscaremos desenvolver o argumento de que, nesse contexto, embora sejam

1- A tese que embasa este artigo (ALVES, 2013) evidencia e caracteriza os aspectos mais relevantes da condição juvenil nesse contexto rural marcado pela cultura da migração. múltiplos os modos de ser jovem, a condição juvenil é fortemente influenciada pela cultura da migração que se desenvolveu na região mineira de Governador Valadares nos últimos anos e que tem como principal característica o transnacionalismo. Tal característica tem afetado os processos de transição para a vida adulta dessa geração, que chamamos de filhos da migração. Esses processos de transição se complexificam na medida em que ocorrem em um contexto marcado por expressões de desigualdade social, com ênfase na sua dimensão simbólica expressa, por exemplo, na tensão: entre os da cidade e os da roça; entre os que emigraram e tiveram sucesso e os que permaneceram ou retornaram frustrados; entre a cultura hegemônica e as culturas populares. $\mathrm{Na}$ análise, partiremos da hipótese de que tais formulações evidenciam demandas de reconhecimento que têm inicialmente na escola, mas também no sonho da migração, algumas das possíveis saídas para afırmação de identidades positivas.

Quando falamos em reconhecimento, partimos das formulações da teoria do reconhecimento de Honneth (2003). Nela, o autor defende a ideia de que a identidade dos indivíduos é construída por meio do reconhecimento intersubjetivo, através do qual os sujeitos garantem a plena realização das suas capacidades e uma relação positiva consigo mesmos. Os indivíduos e grupos só constroem suas identidades e são reconhecidos quando aceitos: a) nas relações primárias, com o próximo - categorizadas como Amor -, o que possibilita desenvolver a autoconfiança; b) nas práticas institucionais e relações jurídicas - categorizadas como Direito -, o que possibilita desenvolver o autorrespeito e a dignidade, e, finalmente, c) nas relações comunitárias, no reconhecimento das realizações ou do caráter dos indivíduos - categorizado como solidariedade -, o que possibilita desenvolver a autoestima.

Segundo o autor, tais dimensões estão imbricadas e o não reconhecimento em algumas dessas dimensões gera o desrespeito, 
que impede a autorrealização do sujeito, gerando uma indignação moral que pode ampliar sua reflexividade e ser o disparador das lutas sociais. Ou seja, para Honneth, a luta por reconhecimento está no âmago dos conflitos sociais, e uma gramática moral rege os conflitos sociais (FUHRMANN, 2013; MENDONÇA, 2009; ALBORNOZ, 2011; FERES JÚNIOR, 2006). Segundo João Feres Júnior (2006), Honneth pretende resgatar o conceito de reconhecimento e utilizá-lo como fundação da teoria crítica: uma teoria crítica que não só dê conta de todas as experiências de privação, discriminação e opressão existentes, como também aponte para meios de superá-las.

\section{Os sujeitos da pesquisa}

0 estudo que dá origem a este artigo foi desenvolvido por meio de uma etnografia, entre os anos de 2009 e 2013, com jovens estudantes do ensino médio moradores de um município rural da região de Governador Valadares, em Minas Gerais, polo das migrações internacionais nas últimas décadas. Os instrumentos utilizados para coleta de dados foram a observação direta e participante, questionários e entrevistas. Os dados foram analisados à luz de um referencial teórico multidisciplinar (da sociologia da juventude, da sociologia da migração, da sociologia rural, da educação e da antropologia).

A investigação foi desenvolvida com estudantes da única escola de ensino médio do município rural de São Geraldo da Piedade, doravante denominado apenas pela sigla SGP. No ano letivo de 2010, estavam matriculados na etapa final da educação básica 306 estudantes, dos quais 195 responderam ao questionário (alunos frequentes ao final do ano letivo). Apesar da presença de adultos matriculados - uma necessidade, já que o município não oferecia a modalidade EJA -, os jovens estudantes em idade regular (15 a 17 anos) eram maioria no grupo, perfazendo um total de $66,7 \%$ das matrículas, acima da média nacional, que era de 50,9\% de acordo com o Instituto de Pesquisa Econômica
Aplicada (IPEA) em 2010. Esses estudantes eram, majoritariamente, moradores da zona rural, ou seja, de fora da sede do município (79\% dos matriculados). Quanto à constituição familiar, 93,8\% eram solteiros e apenas 2,6\% tinham filhos. De acordo com as categorias de identidade étnico-racial adotadas pelo Instituto Brasileiro de Geografia e Estatística (IBGE), $63,6 \%$ se autodeclaram pardos, $16,4 \%$ pretos, 11,3\% brancos, 6,2\% amarelos e 2,1\% indígenas. $\mathrm{Na}$ época da aplicação do questionário, 13,3\% dos pais e 3,1\% das mães viviam em outra cidade (quase todos em outro país). Embora não tenham sido inqueridos a respeito disso no questionário, a pesquisa qualitativa constatou um grande número de pais retornados, evidenciando uma tendência de reunificação familiar que, segundo os moradores da comunidade, estava acontecendo nos últimos anos, possivelmente um reflexo da crise financeira nos Estados Unidos e Europa.

\section{Que rural é esse?}

Nas últimas décadas, a sociedade brasileira vem testemunhando um fenômeno de inchaço dos grandes centros urbanos, que alimenta a tese da urbanização do Brasil. 0 agrônomo José Eli da Veiga (2003), entretanto, defende que tal tese há que ser repensada, uma vez que o país contabilizava, na virada de século XX para o XI, mais de mil municípios com menos de dois mil habitantes. De acordo com a legislação vigente desde o Estado $\mathrm{Novo}^{2}$, classifica-se como cidade toda e qualquer sede de município ou de distrito e, com essa classificação, o censo de 2000 contabilizava uma população urbana de quase 118 milhões de pessoas. É desse modo que mais de $80 \%$ da população brasileira é considerada urbana, o que justificaria a tese de urbanização do Brasil, contestada por Veiga (2003).

Para lidar com as dificuldades conceituais ocasionadas pela obsolescência metodológica

2- Decreto-lei 311/38. 
do cálculo utilizado para definir o rural e o urbano no Brasil, Eli da Veiga sugere que "não se deveriam considerar urbanos os habitantes de municípios pequenos demais, com menos de 20.000 habitantes" (VEIGA, 2003, p. 32), alegando que aspectos como densidade demográfica e localização também precisam ser considerados. Isso porque moradores de municípios pequenos, mas situados próximos a grandes aglomerações urbanas, ou que integram uma região metropolitana, certamente terão experiências diferentes de outros que vivem em municípios com a mesma quantidade de habitantes, porém isolados ou distantes dos grandes centros. Para separar um caso de outro, Veiga (2003) argumenta que o critério de densidade demográfica é decisivo, mas sugere que tal defınição seja feita com base no índice de pressão antrópica, indicador que resulta das modificações sofridas pelo meio em virtude da ação humana, da urbanização e da industrialização. Portanto, de acordo com essa orientação, os municípios rurais são aqueles: que se caracterizem por baixa densidade demográfica; que não estejam localizados próximos a um grande centro urbano; cujas atividades econômicas sejam majoritariamente rurais; e nos quais a intervenção humana e o processo de urbanização causem pouco impacto sobre o meio ambiente. Esse é o conceito que estamos utilizando para definir SGP como um município rural.

\section{Principais características do transnacionalismo em SGP}

Bruna tinha 15 anos à época da pesquisa. Ela relata sua experiência com o pai e conta que, quando ele foi embora para os Estados Unidos, apesar da tenra idade, ela já era capaz de perceber o que estava acontecendo, diferente da primeira vez em que o pai se ausentou, da qual ela diz não ter qualquer recordação. "Ele ficou lá dois anos e voltou. [...]. Alguma coisa assim. Aí, antes, ele já tinha ido pra Alemanha, só que eu não lembro bem, porque eu era muito novinha, mas, quando ele foi pros Estados Unidos, eu lembro".

A história dela e de tantos outros moradores dessa região é rica em evidências de que o que estamos presenciando nessa região mineira é um fenômeno migratório que, diferentemente de outros momentos históricos, não se define apenas por pessoas cruzando fronteiras, mas, ao contrário, por pessoas que, às vezes, parecem até desconhecer fronteiras, tal como acontece em outros contextos, conforme evidenciam Basch, Schiller e Blanc (1994). 0 fenômeno recente, definido por essas autoras como transnacionalismo, é caracterizado pela "fluidez de ideias, objetos, capital e pessoas que se movem através das fronteiras" (BASCH; SCHILLER; BLANC, 1994, p. 27). Essa tendência aos movimentos transnacionais pode ser observada desde os anos de 1970, quando a mobilidade em algumas ilhas do Caribe já era bastante intensa. Naquele contexto, alguns estudiosos preferiam identificar os sujeitos dos processos migratórios transnacionais como pendulares (commuters) ao invés de migrantes, enquanto a mobilidade nas ilhas do Pacífico foi tratada por alguns como circulação, ao invés de migração (SCHILLER; BASCH; BLANC, 1995). No contexto analisado pelas autoras, os sujeitos dos processos migratórios podem ser definidos como transmigrantes, uma vez que o processo que se desenvolve é caracterizado por mudanças constantes, tanto no caso dos pendulares como no caso dos que circulam entre as ilhas ou entre uma ilha e o continente. Naquele cenário, o movimento constante (de pessoas, de bens e mercadorias e de remessas) era uma das principais características da mobilidade humana.

Os impactos que o fenômeno da mobilidade provoca nas sociedades de acolhimento têm sido analisados sob diversas perspectivas (MARGOLIS, 1994, 2009; SEABRA, 2006; PORTES, 1999; CEBULKO, 2009). No entanto, há ainda muito a desvelar sobre as mudanças importantes que tal fenômeno provoca nos locais de origem. $\mathrm{Na}$ abordagem 
aqui utilizada, o transnacionalismo, os migrantes não mais partem com o intuito de fincar a bandeira no local de destino, como na época das colonizações, nem mesmo estão fugindo dos horrores das guerras; tampouco partem deixando para trás laços significativos sem perspectivas de retorno. Ao contrário, os laços (de sangue, culturais, sociais, econômicos) permanecem, na maioria dos casos, intactos na origem, como na comunidade aqui analisada. Em SGP, os moradores que vivem fora do Brasil constroem casas na comunidade, investem em imóveis, pagam plano de previdência privada, participam virtualmente das festas e comemorações familiares, enfim, mantêm vivos todos os laços possíveis. Falamos de uma comunidade rural, localizada no interior do Brasil, que passou a testemunhar outro momento na sua história com o aumento da mobilidade territorial dos seus moradores, que protagonizam ou protagonizaram, em algum momento de suas vidas, movimentos migratórios internacionais, sobretudo para os Estados Unidos, mas também, em menor número, para Portugal, Inglaterra, Alemanha e outros países.

À primeira vista, SGP poderia ser apenas mais uma comunidade rural como tantas outras no interior do Brasil. Todavia, a dinâmica migratória internacional imprimelhe peculiaridades que têm influenciado a história, a identidade, os costumes, valores e os modos de vida da população local. Em virtude desse histórico, muitos jovens são-geraldenses cresceram longe de membros da família de primeiro grau - alguns deles separados da mãe, do pai ou de ambos - e viram-se acolhidos por parentes próximos. Para esses jovens, a família e a escola constituem referências institucionais importantes e mostraram-se como espaços onde a categoria filhos da migração ganha lugar privilegiado de problematização. Os familiares ausentes se faziam presentes no cotidiano e na educação dos filhos. A forma de fazê-lo podia até variar, mas não deixava de acontecer, seja por meio de suporte emocional seja por meio de suporte material e financeiro, seja com visitas regulares (anuais ou bienais) para os que possuíam documentos. Os indocumentados se faziam presentes através do envio constante de presentes, de bens de consumo, das remessas financeiras, e, tanto portadores de documentos quanto indocumentados, através da comunicação regular por telefone, internet e, em casos mais raros, por cartas.

$\mathrm{Na}$ comunidade pesquisada, vaivém de pessoas, a circulação de bens, mercadorias, valores monetários e até as referências a outros países fazem parte do cotidiano, nas transações financeiras, nas brincadeiras de crianças, jovens e adultos, nos ditos populares e até nas discussões em família, o que evidencia aspectos empíricos do que Massey e colaboradores (1993) caracterizam como uma cultura da migração. É muito comum os nativos se referirem aos países onde vivem os parentes como se fossem a cidade vizinha. E, às vezes, é o que parece, dada a frequência com que alguns emigrados cruzam a fronteira para visitar os parentes no Brasil, para passar as festas de fim de ano, fechar um negócio ou acompanhar os investimentos financeiros.

Discutiremos, a seguir, os principais aspectos que caracterizam o transnacionalismo em SGP: o movimento de pessoas, as remessas, os bens de consumo, a influência cultural.

Há casos de pessoas que já reemigraram inúmeras vezes, utilizando diferentes estratégias de entrada irregular nos países de destino. Para aqueles que viviam fora do Brasil em condição regular, a situação era o oposto. Eles vinham ao Brasil com certa frequência, para passar o verão, as festas de fim de ano, festividades familiares ou mesmo ficavam um tempo suficiente de férias, em geral durante $o$ inverno no hemisfério norte, até precisar voltar porque os dólares acabaram. A esse respeito, uma jovem diz: "Meu tio Zé fica nessa vida de Estados Unidos e Brasil, a vida inteira. Já tem uns 25, 26 anos assim" (Ana Paula, 21 anos). Como esse, há outros casos na cidade de migrantes que parecem desconhecer fronteiras e viver simultaneamente nas duas nações. Essa 
é uma característica importante do movimento migratório nesse contexto. Essa aparente facilidade para emigrar acaba por influenciar as decisões de quem está "procurando um rumo na vida”, como dizem os jovens ao final do ensino médio. Alguns consideram que é mais fácil sair de lá para outro país do que para uma das grandes capitais brasileiras, visto que a rede ${ }^{3}$ é um elemento que facilita e até estimula a população local a emigrar, em condições muitas vezes desfavoráveis.

Outra característica são as remessas que, embora tenham diminuído desde a crise econômica de 2008, ainda detêm importante papel econômico na região, visivelmente influenciada pelas moedas estrangeiras. Uma visita a Governador Valadares, ou a qualquer pequena cidade da região, deixa claro quem tem ou teve dólares e quem nunca emigrou (a presença dos dólares na cidade lhe rendeu o sugestivo apelido de valadólares). Essas evidências podem ser detectadas, inicialmente, pelo estilo imponente das casas que constroem. A casa própria é o primeiro grande sonho de boa parte dos emigrados. Alguns vivem anos no exterior, morando em situação precária como pudemos constatar durante uma visita em Boston a alguns membros das famílias pesquisadas -, para enviar dinheiro para construir uma grande casa no local de origem.

Durante o tempo em que vivem no exterior, os emigrados enviam as remessas de dinheiro, que são administradas pelos parentes locais e aplicadas na compra de propriedades rurais ou na construção da casa própria, que geralmente se destaca das construções antigas, pequenas e sem nenhum conforto. As casas dos emigrados são grandes, confortáveis, coloridas, luxuosas. Em geral, são sobrados de dois ou três pavimentos para que sejam vistas e admiradas, algumas com um comércio no térreo, para garantir o sustento da família. Há

3- Ligações mantidas entre os locais de origem e de destino das migrações por meio de laços familiares, de amizade, de relacionamento comercial ou afetivo que possam funcionar como elo entre quem parte e quem fica e que, em muitos casos, assumem papel decisivo nos projetos migratórios. quem prefira construir casas térreas, protegidas por muros bem altos para evitar o olhar dos curiosos. A casa bonita como objeto de desejo ficou evidente certa vez quando, ao entrar em um desses imóveis em SGP, percebemos que a família, ao concluir a construção, fotografou a casa, imprimiu duas fotos em tamanho grande, emoldurou e colocou uma em cada parede da sala. Isso evidencia o valor simbólico atribuído à construção das casas. Thalia (17 anos) nos falou certa vez sobre o assunto, explicando que, para eles,

o ponto X da coisa lá [nos Estados Unidos] é melhorar a vida da gente e da família da gente. Porque a gente quer estudar, a gente quer ser inteligente pra saber conversar com todo mundo, isso e tal. Mas a gente quer o quê? A gente quer ter uma casa. A gente não quer ver a nossa família morando na mesma casa com piso de cera.

Podemos entender a ostentação das construções e do mobiliário das casas como expressão da mobilidade social adquirida com os dólares, funcionando simbolicamente como uma forma de afırmação diante da comunidade, do reconhecimento do sucesso alcançado, mesmo que a duras penas.

A facilidade de acesso a bens de consumo importados é outro aspecto característico do transnacionalismo dessa região mineira, onde os moradores não vão ao shopping center, não compram pela internet, tampouco compram de uma importadora. Eles recebem em casa os mais diversos produtos dos parentes que vivem no exterior. Produtos norte-americanos de diversas marcas - perfumes, roupas, tênis e brinquedos infantis - são muito comuns em SGP. Alguns moradores vendem tais marcas em casa e é comum os parentes que vivem em Belo Horizonte ou outra grande cidade optarem por comprar roupas de grifes em SGP ao invés de comprar no shopping da sua cidade, onde, segundo eles, é muito mais caro. As formas como os produtos chegam são diversas. 0 mais 
comum é o envio por parentes ou amigos que vêm de férias, mas há também aqueles que enviam por correios ou até por contêineres, o que já não era tão comum durante o período da pesquisa. Mas muitos moradores relataram a emoção de receber as caixas, cheias de produtos, novos ou usados. A chegada da caixa para uma família é um evento que toda a comunidade noticia. São caixas ou contêineres inteiros com as mais diversas mercadorias, desde roupas, sapatos, lençóis, cremes e perfumes até eletrônicos e eletrodomésticos. 0 acesso aos produtos importados é mais uma evidência da força simbólica da migração, ao possibilitar um acesso diferenciado ao consumo, expressão empírica da afirmação do alcance de um lugar social, real ou imaginário, que possibilita 0 reconhecimento social. Não é só o produto em si, ou a sua necessidade, é mais o valor simbólico da distinção através da chegada da caixa com os produtos diferenciados que alguns poderão exibir pela cidade.

Por fim ressalta-se a influência cultural. Embora a comunidade preserve elementos importantes da cultural local, como as festas tradicionais do Boi de Balaio, o Festival da Banana, as cavalgadas e as festas religiosas, elementos culturais de outros países são introduzidos em seu cotidiano, como nos casos dos bens de consumo já mencionados. Um exemplo disso é a festa do Halloween, que acontecia não apenas nas escolas, mas com envolvimento de toda a comunidade. A comemoração nas ruas foi iniciativa de uma mãe, retornada dos Estados Unidos, onde havia nascido sua filha, àquela época com oito anos. Ao chegar à cidade, a criança, que não teve muita dificuldade de adaptação, dizia sentir falta da festa e a mãe, com auxílio da diretora da escola onde a criança estudava, organizou a primeira festa de Halloween externa ao estabelecimento, e recebeu adesão de quase todas as crianças e famílias da cidade. No ano em que realizamos a pesquisa, a festa envolveu toda a comunidade. As mães prepararam as guloseimas e enfeitaram as casas e as crianças, com suas fantasias, percorreram todas as ruas da pequena cidade e solicitaram nas casas: "Doce ou travessura!".

A influência cultural externa podia ser percebida ainda nos nomes das crianças. Diferente de alguns modismos de nomes americanizados no Brasil, em SGP as crianças os recebem porque nasceram fora do Brasil ou porque seus pais viveram fora e deram nomes estrangeiros aos filhos. É o caso do pequeno Bryan, cujo pai morou nos Estados Unidos e deu ao filho o nome do melhor amigo que fez naquele país.

\section{Famílias transnacionais}

Ao discutir mobilidade humana, uma questão importante a ser problematizada são as razões da partida. Afınal, por que partem? Nesse caso, as respostas estão ligadas ao histórico das migrações nessa região e às redes que se estabelecem, com pontos na origem e no destino dos fluxos, que fazem com que seja mais provável que alguém emigre para um local onde exista alguma expectativa de apoio na chegada. Mas as razões podem variar bastante de um indivíduo para outro ou mesmo de uma família para outra.

As respostas às indagações sobre as circunstâncias que levaram a esse quadro nos revelam histórias diversas, muito embora quase sempre as explicações fornecidas pelos sujeitos não variem muito e endossem as explicações macroeconômicas da migração que já viraram clichê nessa região: "Ah, vou pros Estados Unidos pra melhorar de vida”. 0 então: "Ah, porque lá tem melhores condições que aqui”. $\mathrm{Ou}$ "Porque quero juntar dinheiro pra construir minha casa". Todavia, a convivência cotidiana acaba evidenciando razões diversas e casos específicos. Foi possível identificar pelo menos quatro razões distintas que, combinadas ou isoladamente, produziram diferentes histórias de vida individuais e trajetórias familiares de separação, reunificação e reencontros. Mas, em todas elas, pudemos perceber a perspectiva da 
busca da melhoria de vida, uma possibilidade de mobilidade social que revela também uma demanda pelo reconhecimento social.

Uma das razões que observamos foi o que chamamos de migração circunstancial, em geral influenciada pelas redes, que ocorre em virtude de uma conjuntura específica. Em alguns casos, a migração não era um projeto pessoal, mas a oportunidade surgiu e ela aconteceu. Um jovem nos conta como foi a decisão de emigrar para alguns de seus parentes.

No ano de 2005, meu tio perguntou se minha mãe queria ir e ela falou que não tinha como. Ele tava querendo levar a namorada dele, só que ele queria que alguém da família fosse com ela pra acompanhar na viagem [com travessia pelo México]. [...] Aí minha mãe não podia [por causa dos filhos pequenos] e uma prima minha foi no lugar dela; aí, depois de dois meses que ela tava lá, minha mãe decidiu ir. (Ernesto, 17 anos).

0 caso da mãe do Ernesto, cujo pai já vivia nos Estados Unidos havia dois anos, é ilustrativo. Ela ficou com os dois filhos em Belo Horizonte e o casal não pensava em separar a mãe dos filhos, mas a oportunidade surgiu com um convite, porque alguém precisava de companhia para fazer a travessia pelo México, e a mãe começou a cogitar a possibilidade de emigrar. Ela acabou deixando os filhos com avós e emigrando junto com a prima, já que a família temia que a moça fizesse a travessia sem a companhia de uma mulher.

A família da Ana Flávia (17 anos) também é ilustrativa desse tipo de migração. 0 primeiro tio que emigrou precisava de ajuda para os trabalhos para os quais havia sido contratado nos Estados Unidos e foi levando os irmãos para ajudá-lo. Todos trabalhavam com atividades agrícolas no Brasil e aprenderam a trabalhar na construção civil quando chegaram aos Estados Unidos. Nesse caso, as circunstâncias no destino acabaram por influenciar a decisão na origem.
Outra razão para emigrar é a reunificação familiar, muito comum entre casais que, mesmo não conseguindo uma forma legal de entrar no país estrangeiro, arriscam-se na clandestinidade. Alguns também tentam levar os filhos, mas geralmente de forma legal, já que os pais temem a travessia pelo deserto. Tais tentativas, na maioria das vezes, são frustradas, pois a dificuldade maior, nesse caso, não é financeira, e sim conseguir o visto para entrar legalmente no país, já que esse grupo pode ser caracterizado como "categoria suspeita" (MARGOLIS, 1994), ou seja, mineiros (com o agravante de ser de Governador Valadares), jovens e com fortes indícios de querer se estabelecer no país. Os pais de Ernesto, Ana Paula e Antônio, por exemplo, tentaram algumas vezes, sem sucesso, conseguir o visto para os filhos.

Aí, antes da minha mãe ir, nós tentamos o visto e foi negado. Nós tiramos outro passaporte, porque já tem um carimbado que seu visto foi negado. Então sempre que eles olharem eles vão saber, né? Aí tiramos outro passaporte. Meu pai marcou com a mulher a entrevista e tudo lá e ela ia levar a gente e ele ia passar um papel pra ela como se ela fosse a tutora [...] minha e do meu irmão. Só que não deu certo. Ela queria um dinheiro muito alto e antes ainda da gente poder viajar. Aí nós nunca fomos. (Ernesto, 17 anos).

Também encontramos, nas histórias contadas nessa comunidade, que, em alguns casos, as pessoas emigraram por razões mais subjetivas, que identificamos como fuga de condições adversas, ocasionadas por questões relativas a desigualdades de gênero, desordem familiar ou alguma insatisfação com as condições de vida na comunidade. Nesses casos, a relação entre migração e a luta pelo reconhecimento se fazia mais explícita, para além da dimensão da mobilidade social.

Durante a presença no campo, ouvimos diversas histórias de pessoas (principalmente mulheres) que deixaram a cidade porque 
queriam viver de forma mais independente das tradições locais. É o caso da mãe da Maria Antônia, que, terminando o curso de Pedagogia, resolveu emigrar depois que se separou e, segundo alguns moradores locais, tomou a decisão por vergonha de continuar vivendo ali. A filha, no entanto, atravessou a adolescência enfrentando situações vexatórias por conta da separação dos pais.

A cidade lá é muito pequenininha, então é muito preconceituosa. Então quando meus pais se divorciaram, muitos outros pais afastaram os filhos, não podiam andar comigo, porque eu era filha de pais separados, que "minha mãe era vagabunda" e tal e tal. Eles falaram mais ou menos isso. (Maria Antônia, 17 anos).

Uma tia da Bruna conta que sua filha largou a faculdade quase no final do curso e emigrou para os Estados Unidos porque temia ter o mesmo futuro da maioria das mulheres em SGP, que, quando trabalham, ganham pouco e são subalternas ao marido. Uma mãe, cujos filhos gêmeos emigraram aos 17 anos, conta que, como o pai bebia muito e batia nos filhos, ela resolveu pedir ajuda ao padrinho dos meninos (que, segundo alguns moradores, trabalhava como cônsul ${ }^{4}$ na época) para levar os filhos para trabalharem nos Estados Unidos. Há ainda o caso de uma família cujo pai foi assassinado e os filhos, jurados de morte, tiveram que deixar a cidade, a propriedade da família e a única irmã. Também ouvimos diversos casos de mulheres que deixaram a cidade porque se separaram do marido e não aguentaram a pressão social, ou ainda casos de homossexuais, homens e mulheres, que preferiram viver em uma cidade considerada mais desenvolvida.

4- 0 cônsul é um agenciador responsável pela documentação que viabiliza a saída do país, seja por fronteira terrestre - articulando as redes criminosas responsáveis pela travessia clandestina -, seja pelas fronteiras aéreas - burlando documentos e corrompendo agentes para facilitar a entrada do migrante no país de destino. Sobre a travessia de migrantes pela fronteira terrestre entre México e Estados Unidos, consultar, entre outros, Moreira (2014).
Por fim, foi possivel identificar diversos casos de reemigração, ou seja, de pessoas que voltaram a emigrar depois do primeiro retorno, corroborando a tese de Lee (1980) de que quem emigra a primeira vez está mais propenso a voltar a fazê-lo. São casos como: o do pai de Bruna, que viveu dois anos nos Estados Unidos, retornou a SGP e, depois de um ano, emigrou para a Alemanha; o do pai da Thalia, que esteve nos Estados Unidos pelo menos três vezes; e de alguns dos tios da Bárbara, que também reemigraram.

Independente da razão que leve à separação dessas famílias, esse é um aspecto que afeta de forma significativa tanto a vida dos pais como dos jovens, alguns dos quais diziam se sentir órfãos de pais vivos. Os relatos emocionados, e por vezes ressentidos, faziamnos lembrar um adágio popular muito comum no interior do nordeste brasileiro: "São Paulo é terra onde filho chora e mãe não vê". Para os jovens nordestinos, onde a migração interna é um dos fatores de separação familiar mais significativo e que teve, durante muito tempo, São Paulo como o principal destino, a saída da casa dos pais é um importante marcador de transição para a vida adulta. Eles não apenas deixam a casa dos pais (alguns dos quais emigraram para São Paulo quando os filhos eram crianças), mas deixam os pais para trás, afastam-se geograficamente, a uma longa distância, embora dentro do seu próprio país.

No caso das famílias de SGP, elas se reorganizam, reestruturam a disposição dos membros, de modo a se apoiarem mutuamente, criando arranjos tanto no local de origem como de destino para garantir não apenas o suporte financeiro, mas sobretudo emocional de que precisam para enfrentar a separação. Apesar do distanciamento físico, os laços de afetividade, cuidado e solidariedade da família perduram. Um desses casos é o de uma família de quatro filhos (um rapaz e três moças) dividida pela migração. 0 rapaz emigrou e levou, uma de cada vez, as duas irmãs mais velhas, deixando a caçula com a mãe. Ele foi deportado depois de 
dez anos vivendo nos Estados Unidos e as duas irmãs lá permaneceram, apoiando-se e dando prosseguimento ao sonho de juntar dinheiro para voltar ao Brasil. A mãe, zelosa tanto com os que ficaram quanto com os que partiram, mostrava-se preocupada com o estilo de vida das duas filhas que vivem nos Estados Unidos:

Minhas filhas não aproveitam nada da vida. Só ficam trabalhando. Tem uma que quando liga nem quer muito saber das festas por aqui. Só pergunta como eu tô e pronto, desliga. Eu acho que ela se arrependeu muito de ter ido, mas agora não tem volta, não terminou os estudos, vai fazer o quê? (NOTAS DE CAMPO - 01/12/10).

Portanto, em SGP, havia casos de filhos da migração que se separaram dos pais ainda na infância, e também aqueles que o fizeram na juventude. Ambos vivenciaram situações típicas do transnacionalismo nessa comunidade, pelo que é possível afırmar que esses jovens viveram uma condição juvenil com singularidades e passaram por um processo de transição para a vida adulta diferenciado em virtude do fenômeno migratório.

\section{A transição para a vida adulta}

Os sujeitos deste estudo são considerados jovens de acordo com a legislação brasileira, visto que compõem a coorte geracional entre 15 e 29 anos de idade. Além disso, também compartilham de outros aspectos da vida que caracterizam a juventude: são solteiros, frequentam a escola, não têm filhos, vivem com a família de origem e dependem financeiramente dos pais. Para boa parte dos jovens brasileiros, os marcadores principais de transição para a vida adulta são: o término dos estudos, a saída da casa dos pais e a constituição de um núcleo familiar. Para muitos jovens de SGP, além desses marcadores tradicionais, a separação dos pais, ocasionada pelo deslocamento geográfico, é outro aspecto que tem se mostrado crucial nesse processo, evidenciando que a influência das migrações pode produzir modelos próprios de transição para a vida adulta. Nesses casos, as demandas por reconhecimento, expressas no desejo/expectativas da mobilidade social, interferem nos processos de subjetivação desses jovens, gerando muitas vezes sofrimentos e traumas que irão marcar de alguma forma suas trajetórias de vida.

Os modelos de transição para a vida adulta marcados por lógicas próprias são problematizados por Pais, Cairns e Pappámikail (2005), por meio da ideia de trajetórias fragmentadas, que se refere-se a um processo que se desenvolve a partir de uma lógica que remete às diferentes condições juvenis. Esses autores falam ainda de múltiplas transições que, embora não sejam diretamente para o mundo adulto, fazem parte do caminho como uma etapa da transição, como, por exemplo, a transição da escola secundária para o ensino superior, o que nos instiga a repensar e reelaborar modelos analíticos de transição na contemporaneidade. Podemos afirmar com Pais, Cairns e Pappámikail que as transições tendem cada vez mais a serem individualizadas.

Em SGP, o processo de transição para a vida adulta era vivenciado por muitos jovens longe de membros importantes da família, instituição por excelência detentora de credenciais significativas nesse momento da vida (afetivas, materiais, culturais). A ausência do pai, da mãe ou de ambos em alguns casos imputava às famílias a promoção de rearranjos para tentar suprir as demandas provocadas pelas ausências, como evidencia o caso de Thalia:

E... assim... meu tio Mauro foi... meu tudo. A minha figura masculina né... de referência. Foi ele. Então, eu aprendi a andar de cavalo com ele, de bicicleta com ele. Aí eu... tipo, quando ele ia sair, ele falava pra mim quando ele ia sair. E sempre ele me levava porque, né, eu gostava demais, sei lá como é isso. Aí foi isso, né, essa convivência. Aí meu pai voltou, aí eu achei estranho, que 
eu não queria aquele pai, não. Eu queria o outro, meu tio. (Thalia, 17 anos).

0 rearranjo familiar, no caso dessa jovem, visava a suprir a ausência do pai, cuja figura foi substituída pela do tio, com quem ela conviveu mais de perto desde criança e que também emigrou quando ela estava entrando na puberdade. Esses fatos foram marcantes em sua vida e ela se dizia ainda bastante perdida, sem entender algumas situações que a afetavam. Esse processo pode ser doloroso e conflituoso, como diz uma jovem, quando conta sobre as dúvidas que tinha quando entrou na puberdade e não tinha a mãe por perto e teve de contar com uma tia para atravessar as turbulências da fase: "A minha avó, mãe do meu pai, [...] ela acha que beijar na boca é um absurdo" (Maria Antônia, 18 anos).

Outro caso emblemático foi o da jovem Ana Paula e seu irmão, que, embora tenham ficado morando com tias, uma delas professora da escola estadual, tiveram um processo de escolarização marcado por reprovações, porque, segundo a escola, eles viveram durante algum tempo sob a expectativa de emigrar para os Estados Unidos e, por isso, não se interessavam pelos estudos. Além disso, os pais enviavam-lhes altos montantes em dinheiro, provavelmente para suprir a ausência, o que levou esses dois jovens a fiarem-se, durante algum tempo, na ideia de que não precisariam estudar. Depois da crise de 2008, as remessas foram reduzidas quase a zero, segundo eles próprios relataram, e os dois concluíram o ensino médio, ela aos 21 anos e ele aos 19 anos de idade. A essa altura, já convictos de que precisariam estudar para dar um rumo à vida.

A ausência da família, em muitas ocasiões, reverberou na vida escolar, com alguns casos-limites de jovens que passaram a adotar postura de rebeldia por se sentirem abandonados pelos próprios pais:

Eu tinha 10 anos quando meu pai foi embora e 11 quando a minha mãe foi. Para mim, era meu castigo. 0 que eu tinha feito a Deus para merecer uma coisa dessas? Aí eu fiquei revoltada. (Maria Antonia, 18 anos).

Tenho 21 anos e minha mãe foi embora eu tinha 12, meu irmão tinha nove. Lógico que a gente sentiu muito, mas acho que a gente acabou acostumando. (Ana Paula, 21 anos).

Nessas situações, não nos parece que esses pais possam ser julgados na perspectiva da “demissão parental” (DIOGO, 2010), mas que estavam enredados em dinâmicas culturais próprias - seja a cultura da migração seja a falta da cultura escolar - que impunham limites à relação dessas famílias com a escola.

Observamos outro aspecto que marca a transição e que guarda estreita relação com a mobilidade humana: os papéis assumidos na família pelos jovens, em geral tomando o lugar dos pais ou de irmãos mais velhos que partiram. Algo que era comum à maioria dos jovens que colaboraram com esta investigação era todos trabalharem. Seja o trabalho remunerado formal, seja o trabalho produtivo na propriedade da família (em geral, sem receber salário, apenas o custeio dos gastos com lazer), seja o trabalho doméstico familiar, considerado nesse grupo como uma obrigação das meninas e que não lhes rendia qualquer remuneração. Nesse contexto, a condição juvenil não se define pela moratória para o período de estudos ou de momentos de lazer e sociabilidade, mas agrega esses aspectos ao trabalho e às responsabilidades no seio da família, como explica o jovem Dil (19 anos), o mais novo de uma família de três irmãos, que, mesmo sem ter concluído o ensino médio, viu-se obrigado a assumir a responsabilidade pela propriedade rural da família, aos 17 anos, quando os irmãos mais velhos emigraram para os Estados Unidos. Ele fala da sua condição de trabalhador-estudante: "Uma hora eu sou estudante, outra hora eu sou trabalhador. É difícil ter que mudar 
de vida o tempo todo durante o dia...”. Esse jovem acordava às quatro horas da manhã, trabalhava tirando leite, depois ia para escola, voltava ao trabalho na roça e nem sempre conseguia parar no meio da tarde para estudar e também não conseguia estudar à noite porque já estava cansado e precisava acordar cedo para começar tudo de novo. Dizia não estar certo de que permaneceria trabalhando na propriedade da família depois que não tivesse mais os pais. 0 pai tinha 84 anos e Dil evitava que ele fizesse trabalho pesado, pois não tinha mais condições para tal, no seu entendimento. Ele relatou que, ao ingressar no ensino médio, achava que não daria conta de conciliar, pensou em desistir dos estudos, mas sabia que era preciso estudar se quisesse deixar o trabalho pesado na roça.

Casos como o do jovem acima mencionado ilustram a centralidade do nível médio de ensino nesse contexto, fortalecido pela baixa escolaridade dos pais, que consideram a conclusão do ensino médio uma importante conquista. 0 término da escolarização básica tem se mostrado um momento crucial na definição dos projetos de vida dos jovens brasileiros de um modo geral e, para esse grupo de jovens do meio rural, esse rito de passagem é ainda mais claro. Concluir o ensino médio significava ter que tomar a principal decisão das suas vidas: permanecer em SGP ou emigrar, seja para uma das cidades da região, para outro país (as duas opções mais comuns), para a capital do estado ou para outro estado do Brasil. Tal realidade expressa um contexto social no qual a escolaridade se torna um dos poucos meios, além da migração, através dos quais é possível sonhar com a mobilidade social e o consequente reconhecimento social.

A valorização da educação escolar por essas famílias está, de certa forma, ligada ao histórico das migrações, visto que muitos dos emigrados não estudaram e suas biografias são, em certa medida, comparadas às de outros membros da comunidade que optaram pelos estudos ao invés da migração. As notícias dos parentes emigrados que viviam e trabalhavam em condições difíceis no exterior, bem como as próprias histórias de vida dos retornados, eram constantemente avaliadas. Ademais, os jovens eram sistematicamente aconselhados a estudar para não precisarem passar pelas mesmas situações de sofrimento dos que emigraram, como eles dizem: "Brasileiro lá é tratado como cachorro. Porque eles sofreram demais." (Bárbara, 17 anos).

Histórias como essas eram comuns na região, sobretudo de quem se aventurou na travessia pelo México. Os jovens falavam sobre a situação dos parentes emigrados, as vantagens e desvantagens de emigrar, os pontos positivos e negativos da vida fora do país e, em muitos casos, a decisão de emigrar encontrava no modo de entrada no país de destino o primeiro ponto de resistência. Durante o período em que lá estivemos, ouvimos diversas histórias de pessoas que fizeram a travessia, umas relatadas com muita dor e sofrimento; outras, no entanto, talvez por vergonha, tentavam minimizar a experiência, afırmando que não enfrentaram qualquer dificuldade, o que era desmentido sistematicamente.

Houve quem se referisse à travessia do deserto, na fronteira do México com os Estados Unidos, como "o inferno aqui na terra" e, em relatos mais emocionados, ouvimos pessoas dizerem que pediram para ser pegos pelo serviço de imigração ou para morrer, pois não viam outro jeito de acabar com aquele sofrimento. A morte, aliás, em alguns casos, acabava por ser o destino de alguns que investiram nessa empreitada. Quando chegamos ao campo de pesquisa, em setembro de 2010, os moradores da região ainda estavam aturdidos com a notícia de dois jovens da cidade vizinha, Sardoá, que haviam sido assassinados em uma chacina perto da cidade de San Fernando, na fronteira do México com os Estados Unidos, quando esperavam pelos coiotes que os guiariam na travessia (MOREIRA, 2014). Essa realidade retrata de forma evidente o sofrimento, o esforço e as consequências subjetivas da escolha de melhorar de vida em um contexto no qual a dimensão econômica, o 
se dar bem na vida parece ser o principal vetor simbólico de reconhecimento social.

\section{A difícil busca por ser alguém na vida}

Uma das mais importantes constatações deste estudo foi que o projeto de vida dos jovens naquele contexto rural, marcado pelo transnacionalismo, era "ser alguém na vida". Esse era o objetivo do grupo pesquisado e, para muitos, esse objetivo seria atingindo por meio da educação, e a migração internacional era um plano B. Era evidente para aquele grupo a forte crença na escola como o caminho para uma vida melhor, crença que não era apenas dos jovens, mas de toda a família. Ouvimos de muitos pais, mães, avós e tios a frase: "Eu não estudei, mas quero estudar meu filho" ou neto, sobrinho etc.

Para muitos jovens, sobretudo os moradores e trabalhadores do campo, a escola era detentora de uma credencial para uma vida melhor, capaz de livrá-los, no presente e no futuro, da dureza do dia a dia, do trabalho cansativo na roça ou no curral. Essa era a grande razão pela qual, apesar das dificuldades enfrentadas para acessar e permancer na escola, esses jovens acreditavam nela como o caminho para uma vida melhor. ${ }^{5}$

Mas o que afinal eles tinham em mente quando afırmavam que queriam ser alguém na vida? Como assim? - perguntávamos insistentemente - Vocês não são? E fomos tentar entender o que significava essa expressão para aqueles jovens:

Ser alguém na vida é você ser reconhecido na sociedade. Você desenvolver um serviço onde você pode ser conhecido, igual eu falei. Ser conhecido, eu considero assim, é você ajudar realmente quem precisa, porque quem ajuda as pessoas é reconhecido na sociedade. (Netim, 19 anos).

5- Nos limites deste artigo, não é possivel aprofundar na reflexão da relação dos jovens com a escola. Para ampliar esse debate, ver Alves (2013).
A demanda por reconhecimento e por autonomia apareceu em diversas ocasiões na fala desses jovens. Para eles, ser alguém na vida significava ser reconhecido, ter o respeito da sociedade, ser enxergado e conhecido. Ser ouvido e respeitado. Ser valorizado. Ser cumprimentado ao passar na rua. Receber um bom dia. Ser tratado com dignidade pela polícia e pelas outras autoridades da cidade. Não ser tratado como "gente da roça", ignorante, invisíveis aos olhos dos moradores da cidade. Enfım, sair da condição de invisibilidade, deixar de ser um "zé-ninguém”, como nos falou certa vez um jovem morador da comunidade rural do Vinhático, a mais pobre do município, habitada majoritariamente por negros e cujos estudantes foram os que se mostraram mais desfavorecidos em termos de inclusão social. Para os jovens dessa comunidade, as reclamações dentro da escola sobre preconceito, discriminação negativa, racismo e invisibilidade pública foram mais evidentes que para os de outras comunidades rurais e para os moradores da sede.

0 que esses jovens pareciam nos dizer era que queriam ser reconhecidos como alguém com alguma importância, algum valor, ser incluídos na ordem social e na aceitação de seus valores. Parece-nos que evidenciavam a existência da produção social de uma determinada categoria de pessoas tidas como ninguéns, como inexistentes socialmente. Ou seja, os padrões culturais, os valores, os comportamentos próprios da história e trajetória desses indivíduos - "os da roça”, "os pretos” - são negados, não são reconhecidos como válidos. E isso ocorre na comparação com outro conjunto socialmente reconhecido, hegemônico, que serve de medida para a negação do Outro: "os da cidade", "os brancos". E caso aspirem a "ser alguém”, esse processo implica negar os padrões de origem e assumir os padrões dominantes. É a clássica relação Nós versus outros, predominante na colonização e que se reproduz até hoje.

Eles tinham claro que, para ser alguém na vida, era muito importante a inserção no sistema 
produtivo por meio de uma atividade laboral que lhes garantisse as condições para assumirse como um membro autônomo da sociedade. Contudo, tal inserção não era suficiente. Ser alguém na vida é muito mais do que conquistar um lugar no mercado de trabalho; é ter um lugar que lhes permita ser reconhecido como um membro da sociedade, como um cidadão, e, para isso, eles tinham clareza de que a educação tem um papel importante: "A gente quer estudar, a gente quer ser inteligente pra saber conversar com todo mundo" (Thalia).

Nesse sentido, eles acreditavam que era a escola que ia ensiná-los a falar sobre questões que os desafiavam na vida, saber conversar, se expressar, conseguir serem vistos, valorizados e não serem julgados como "gente da roça". Certa vez, perguntada sobre o que esperava da escola, uma jovem respondeu que a escola deveria ensiná-los “a entrar e sair”, explicando com palavras que não podemos reproduzir fielmente, mas que tinham o sentido de que ela deveria ensinar-lhes a vencer na vida, ensinar a pessoa a se virar em diferentes contextos. Isso para ela era "saber entrar e sair", ou seja, saber como se comportar de acordo com as expectativas do lugar. Ela alegava que, como os pais, por serem da roça, desconheciam muita coisa importante que ela sabia que iria precisar para a vida fora dali, era isso que ela esperava da escola, ou seja, além de aprender a ler e escrever, que ela pudesse ir além do que seus pais pudessem lhe ensinar. Esse posicionamento dos jovens em relação aos saberes escolares corrobora as críticas ao afastamento do currículo das demandas e reais necessidades dos estudantes.

E aqui nos deparamos com uma tensão. Os jovens sabiam da necessidade do domínio das normas e comportamentos hegemônicos necessários para se virar na vida, mas isso implicava muitas vezes a negação da cultura de origem. Pudemos perceber que na escola predominam valores, normas, padrões de linguagem e de comportamento próprios das camadas médias, que são tomados como referência de um ideal de ser humano a ser alcançado e vivenciado. São esses padrões meritocráticos, seletivos e segregadores que predominam na organização escolar e se tornam muitas vezes a referência de um Nós expresso nos setores incluídos da sociedade. Diante de tais padrões, buscam, pelo menos no discurso, tornar iguais os Outros, os jovens pobres, produzidos tão desigualmente! (ARROYO, 2014, p. 183). Segundo Arroyo, há um confronto entre Nós, racionais, cultos, civilizados, e os Outros, carentes de saberes e de valores, ignorantes, irracionais, com problemas de aprendizagem e de conduta ou até mesmo violentos, ameaçadores. Mesmo que essas representações não sejam explicitadas normalmente no cotidiano escolar, elas estão presentes subliminarmente. Daí sua eficiência.

Nessa busca por entender o significado de ser alguém na vida, constatamos que atingir a maioridade também não é suficiente e, em alguns casos, poderia ser até um ponto negativo para os que passavam a sentir-se um fardo para a família. Além da idade, esses jovens também precisavam atingir uma determinada condição de autonomia e independência financeira para sentirem que estavam, de fato, tornando-se membros da sociedade. Completar 18 anos para eles pouco adiantava se continuassem sob a tutela e dependência financeira dos pais. No meio rural, as possibilidades de conquistar alguma autonomia financeira são escassas. Para os rapazes, os trabalhos esporádicos na roça ou na propriedade rural da família lhes rendiam ajuda de custo para a diversão do fim de semana. Para as moças, uma faxina, um trabalho como manicure ou mesmo vender algumas hortaliças na sede do município eram algumas das possibilidades. No entanto, essas eram iniciativas individuais e cujo retorno financeiro não lhes garantia qualquer segurança para ancorar seus projetos de vida. Os que tinham parentes fora do país contavam com as remessas dos familiares para arcar com os custos de lazer e sociabilidade (embora isso venha diminuindo sistematicamente), mas eram poucos os que faziam planos de investimento 
com a ajuda financeira que recebiam. Dessa forma, na busca por ser alguém na vida, ou na busca por reconhecimento, os jovens viam a escola como uma saída possível e a migração aparecia como uma segunda alternativa. Ambas como uma possibilidade de se afirmar diante da invisibilidade, das discriminações e preconceitos que enfrentam como jovens pobres no meio rural.

No contexto investigado, são múltiplos os modos de ser jovem e a condição juvenil carrega importantes marcas da cultural local, mas também aspectos globais, proporcionados pela cultura da migração e pelo transnacionalismo. Muitos jovens dessa geração de filhos da migração - cujos pais partem e os deixam aos cuidados de outros membros da família -, mas também os jovens que partem, deixando os pais para trás, têm a juventude marcada pelos deslocamentos familiares. Parece-nos que o transnacionalismo se estabelece como um elemento a mais na complexidade das relações locais marcadas pela desigualdade. Nessa perspectiva, o ser alguém na vida se constitui como uma expressão da busca de reconhecimento através do qual principalmente os jovens da roça querem sair da invisibilidade, querem ser reconhecidos como alguém, ser incluídos na ordem social e reconhecidos como cidadãos no seu sentido pleno, em um contexto que insiste em reproduzi-los como subcidadãos.

\section{Referências}

ABRAMO, Helena Wendel. Condição juvenil no Brasil contemporâneo. In: ABRAMO, Helena Wendel; BRANCO, Pedro Paulo Martoni. Retratos da juventude brasileira: análises de uma pesquisa nacional. São Paulo: Instituto Cidadania; Fundação Perseu Abramo, 2005.

ALBORNOZ, Suzana Guerra. As esferas do reconhecimento: uma introdução a Axel Honneth. Cadernos de Psicologia Social do Trabalho, São Paulo, v. 14, n. 1, p. 127-143, 2011.

ALVES, Maria Zenaide. Ser alguém na vida: condição juvenil e projetos de vida de jovens moradores de um município rural da região de Governador Valadares/MG. 2013. Tese (Doutorado) - Faculdade de Educação da UFMG, Belo Horizonte, 2013.

ARROYO, Miguel. Os jovens, seu direito a se saber e o currículo. In: DAYRELL, Juarez; CARRANO, Paulo; MAIA, Carla Linhares. Juventude e ensino médio: sujeitos e currículos em diálogo. Belo Horizonte: UFMG, 2014. p. 157-204.

BASCH, Linda; SCHILLER, Nina Glick; BLANC, Cristina Szanton. Nations unbound: transnational projects, postcolonial predicaments and deterritorialized nation-states. New York: Routledge, 1994.

BRASIL. Decreto-lei n. 311 de 2 de março de 1938. Dispõe sobre a divisão territorial do país e dá outras providências. Senado Federal, Brasília, DF, 1938. Disponível em: <http://legis.senado.gov.br/legislacao/ListaPublicacoes.action?id=32235>. Acesso em: 05 out. 2012.

CEBULKO, Kara Beth. Documented, undocumented and somewhere-in-between: documentation status and the incorporation of children of Brazilian immigrants. Indiana: College of Arts and Sciences in the Department of Sociology Indiana University, 2009.

DAYRELL, Juarez. A música entra em cena: o rap e o funk na socialização da juventude. Belo Horizonte: UFMG, 2005.

DIOGO, Ana Matias. Do envolvimento dos pais ao sucesso escolar dos filhos: mitos, críticas, e evidências. Sociologia da Educação, Rio de Janeiro. v. 1, p. 71-96, 2010. Disponível em: <http://www.maxwell.lambda.ele.puc-rio.br/rev_sociologia_edu. php?strSecao=input0 $>$. Acesso em: 22-04-13.

FERES JÚNIOR, João. Aspectos semânticos da discriminação racial no Brasil: para além da teoria da modernidade. Revista Brasileira de Ciências Sociais, São Paulo, v. 21 n. 61, p. 164-176, jun. 2006.

FUHRMANN, Nadia. Luta por reconhecimento: reflexões sobre a teoria de Axel Honneth e as origens dos conflitos sociais. Barbarói, Santa Cruz do Sul, n. 38, p. 79-96, jan./jun. 2013. 
HONNETH, Axel. A luta por reconhecimento: a gramática moral dos conflitos sociais. São Paulo: Editora 34, 2003.

IPEA - Instituto de Pesquisa Econômica Aplicada. Migração interna no Brasil. Comunicados do IPEA, Brasília, DF, n. 61, 17 ago. 2010. Disponível em: <http://www.ipea.gov.br/agencia/images/stories/PDFs/comunicado/100817_comunicadoipea61.pdf>. Acesso em: 17 dez. 2012.

LEE, Everett. Uma teoria sobre a migração. In: MOURA, Hélio A. de (Coord.). Migração interna: textos selecionados. Fortaleza: BNB/ETENE, 1980. p. 217-244.

MARGOLIS, Maxine L. An invisible minority: Brazilians in New York City. Gainesville: UP of Florida, 2009. Revised and expanded edition.

MARGOLIS, Maxine L. Little Brazil: an ethnography of Brazilian immigrants in New York city. New Jersey: Princeton University Press, 1994.

MARGULIS, Mario L. (Org.). La juventude es más que una palavra. Buenos Aires: Biblos, 2000.

MASSEY, Douglas et al. Theories of international migration: a review and appraisal. Population and Development Review, v. 19, n. 3, p. 431-466, sept, 1993.

MENDONÇA, Ricardo Fabrino. Dimensão intersubjetiva da auto-realização: em defesa da teoria do reconhecimento. Revista Brasileira de Ciências Sociais, São Paulo, v. 24, n. 70, p. 143-154, jun. 2009.

MOREIRA, Júlio da Silveira. Violência contra migrantes em trânsito pelo México. 240 f. 2014. Tese (Doutorado em Sociologia) - Universidade Federal de Goiás - UFG, Goiânia, 2014.

PAIS, José Machado; CAIRNS, David; PAPPÁMIKAIL, Lia. Jovens europeus: retrato da diversidade. Tempo Social, São Paulo, v. 17, n. 2, p. 109-140, nov. 2005.

PORTES, Alejandro. Migrações internacionais: origens, tipos e modos de incorporação. Oeiras: Celta, 1999.

SCHILLER, Nina Glick; BASCH, Linda; BLANC, Cristina Szanton. From immigrant to transmigrant: theorizing transnational migration reviewed work(s). Anthropological Quarterly, v. 68, n. 1, p. 48-63, jan. 1995.

SEABRA, Teresa. A relação das famílias imigradas com a escolaridade: comparando as famílias de origem cabo-verdiana e as de origem indiana. Lisboa: Interacções, Lisboa, v. 2, n. 2, p. 141-154, 2006. Disponível em: <http://revistas.rcaap.pt/interaccoes/ article/view/294/250>. Acesso em: 28 nov. 2006.

VEIGA, José Eli da. Cidades imaginárias: o Brasil é menos urbano do que se calcula. Campinas: Autores Associados, 2003. 304 p.

Recebido em: 30.11.2014

Aprovado em: 11.03.2015

Maria Zenaide Alves é doutora em educação pela Universidade Federal de Minas Gerais (UFMG), com estágio sanduíche na Columbia University. É professora na Universidade Federal de Goiás - campus de Catalão (UFG).

Juarez Tarcisio Dayrell é doutor em educação pela Universidade de São Paulo e pós-doutor pelo Instituto de Ciências Sociais da Universidade de Lisboa. Atualmente, é professor associado da Universidade Federal de Minas Gerais (UFMG) e pesquisador do Conselho Nacional de Desenvolvimento Científico e Tecnológico (CNPq). 